\title{
moroseopy tophy
}

nOVEMBER I 996

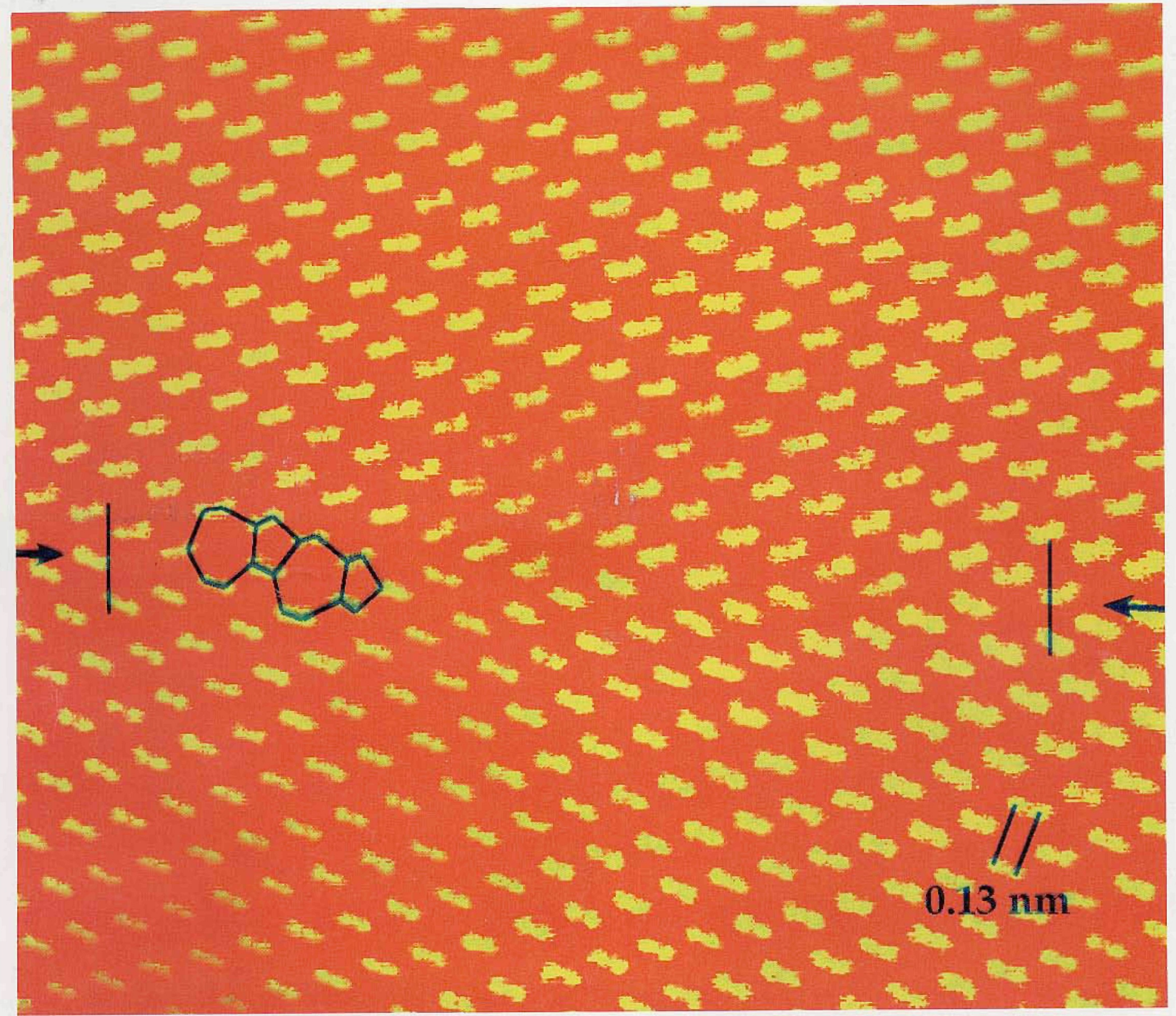



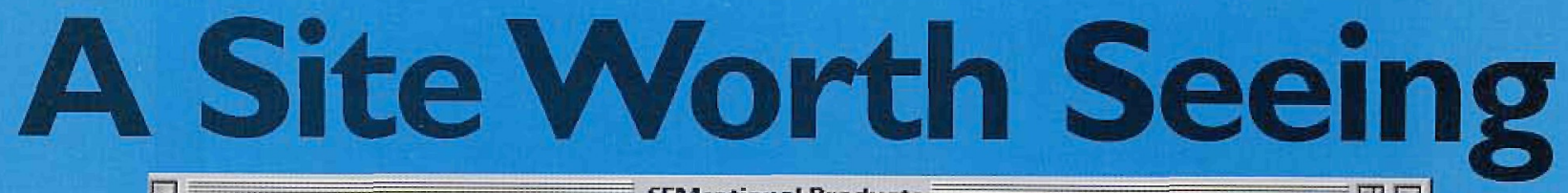

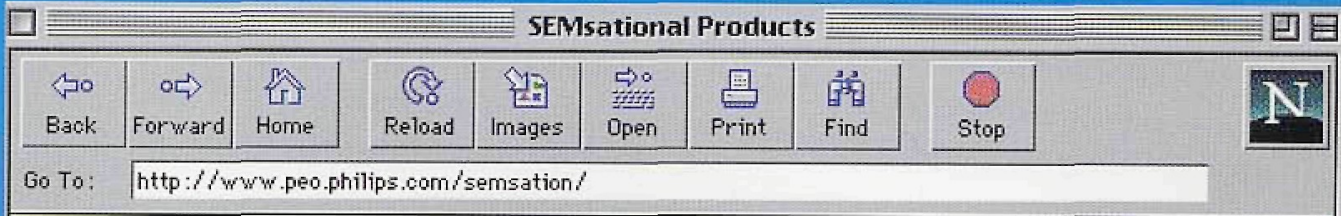

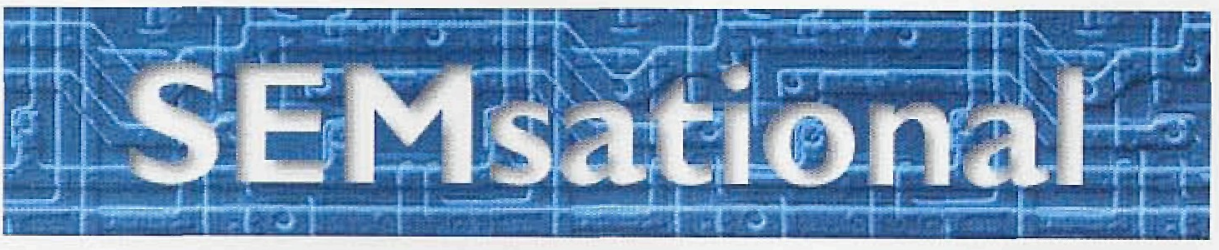

\section{Scanning Electron Microscopy with a Difference...}
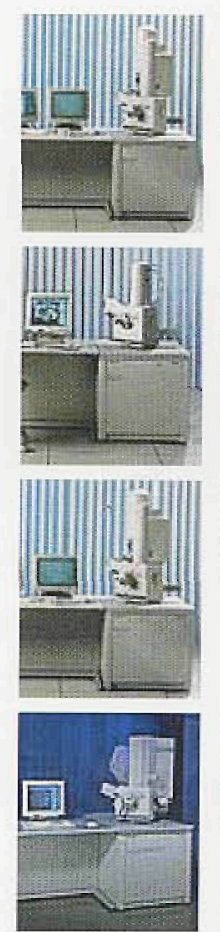

\section{$\mathrm{XL} 20$}

Precision tilt eucentric $20 \mathrm{~mm} \times 20$ mm stage and aresolution down to 4 nm make the XL20 ideal for investigations and small sarnples.

\section{$\mathrm{XL} 30$}

Chamber with manyfree ports, a 50 $x 50 \mathrm{~mm}$ tilt eucentric stage and full system aut omation for increased analytical throughput, including $\mathrm{EDX}$, WDX and EBSP.

\section{X $30 \mathrm{FEG}$}

Same as the XL30 plusa combination of high resolution and uniquely high and stable current ior outstanding analytical perf ormance.

\section{XL30ESEM-FEG}

Feat uring a patented gaseous secondary electron detector system, specimen examination is by means of a FEG electron bearn in an exceptionally high pressure enwironment, compatible with hydrated samples.

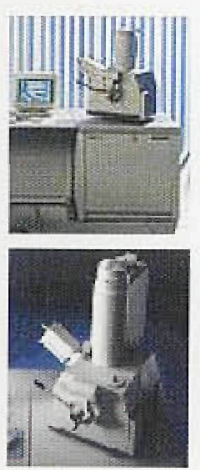

XL40

For large sample analysis, from $1 C$ wafers to high-qualitycoated materials. XL40's features include a. $150 \mathrm{~mm}$ motorized stage and $45^{\circ}$ titting of large planar'specimens.

\section{X $40 F E G$}

A hightech blending of the XL40 [above] wh FEG resolution and stability make this instrument partic ularly suited f or analytical applications.
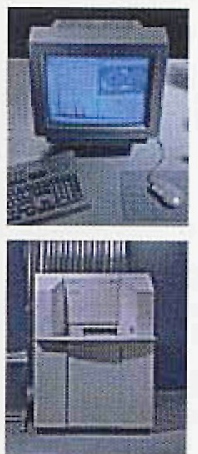

XL-Analytical

The cust onized embedding of EDX in anytype $X L$. A common software emironinent and consistent user interface allows generation of highlevel automation packages.

\section{XL50 FEG-DRT}

This advance dinstrument combines a FEG electron source with a $200 x$ $200 \mathrm{~mm}$, 5axis movement stage. Average stage accuracy is wh hin 1.5 microns across an 8 " wafer.

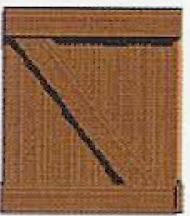

$X L ? ?$

coming soon.
Philips XL Series SEMs reflect the perfect blend of elegant hardware and sophisticated software. System modularity and a choice of electron sources (tungsten; lanthanum hexaboride ( $L a B 6$ ), field emission (FEG)), enable a basic instrument to be configured to specific requirements. Menu-driven point-and-click mouse control contributes to unprecedented user friendliness. Take a look at the Philips XL Series SEMs. You'll find they're simply SEMsational!

\section{Let's make things better.}

Philips Electronic Instruments $\mathrm{Co}$. 85 Mckee Drive, Mahwah, NJ 07430

Fax: 201-529 2252, Telephone: 201-529 3800 E-mail:marcom@eoile.philips.nl Website: wwwpeo.philips.can

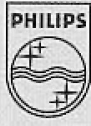

PHILIPS 